\title{
DESAFIOS CONTEMPORÂNEOS PARA A EDUCAÇÃO MUSEAL
}

\author{
CONTEMPORARY CHALLENGES FOR MUSEUM EDUCATION
}

Maria Emilia Sardelich ${ }^{1}$

\begin{abstract}
Resumo
Este artigo tem por objetivo indicar os referênciais teóricos e metodológicos que tem orientado as ações educativas das instituições museológicas de Artes Visuais ao longo do século XX. Por meio de uma pesquisa bibliográfica, apresenta algumas representações de museu, seguidas das principais tendências que tem norteado os serviços educativos. Relaciona os posicionamentos teóricos que procuram responder as demandas colocadas à instituição museal na contemporaneidade. Sinaliza que os referenciais teóricos e metodológicos têm se construído a partir de oposições dicotômicas hierarquizadas entre acervo/coleção e visitante, com a pretensão de que o visitante responda de acordo com as expectativas de curadores e ou educadores. Conclui que pensar um museu do século XXI nos desafia a compreender a linguagem visual como um sistema performativo e como os atos visuais do e no museu endereçam as ações educativas.
\end{abstract}

Palavras-chave: Educação museal. Modos de endereçamento. Performatividade.

\section{Abstract}

This article aims to introduce the theoretical and methodological references that have guided the educational actions of museological institutions of Visual Arts throughout the twentieth century. A bibliographical research presents some representations of museum, followed of the main tendencies that has guided the educational services. Lists the theoretical positions that seek to respond to the demands placed on the museum institution in contemporary times. It indicates that the theoretical references have been constructed from hierarchical dichotomic oppositions between collection and visitor, with the pretension of obtaining the answers anticipated and desired by curators and / or educators. Concludes that thinking a 21 st century museum challenges us to understand visual language as a performative system and how the visual acts of the museum address the educational actions.

Key-words: Museum education. Mode of address. Performative system.

\footnotetext{
${ }^{1}$ A autora é Doutora em Educação pela Universidade Federal da Bahia e Professora da Universidade Federal da Paraíba (UFPB), Centro de Educação (CE), Departamento Metodologia da Educação (DME) e Programa Associado de Pós-Graduação em Artes Visuais (PPGAV UFPB/UFPE). E-mail: emilisar@hotmail.com
} 


\section{Introdução}

Recentemente foi aprovada a Política Nacional de Educação Museal (PNEM), formada por um conjunto de principios com a finalidade de orientar as práticas educacionais em instituições museológicas do Brasil (IBRAM, 2017). A PNEM, aprovada no $7^{\circ}$ Fórum Nacional de Museus (FNM), em junho de 2017, é fruto de uma demanda de profissionais de diferentes áreas e vem sendo gestada há algum tempo. Alguns momentos marcantes dessa gestação ocorreram no ano de 2003, quando o Ministério da Cultura (MinC) lançou as bases da Política Nacional de Museus com o fim de promover a valorização, a preservação e a fruição do patrimônio cultural brasileiro (BRASIL, 2003); o Decreto n. ${ }^{\circ} 5.264$, de 5 de novembro de 2004, que instituiu o o Sistema Brasileiro de Museus (SBM) e, em 2006, o Cadastro Nacional de Museus e o Observatório Nacional de Museus e Centros Culturais. O I ${ }^{\circ}$ Encontro de Educadores do Instituto Brasileiro de Museus (IBRAM), que ocorreu no Museu Imperial de Petrópolis, em 2010, foi outro evento relevante dessa gestação, pois teve por objetivo traçar diretrizes e estratégias para a elaboração da politica educacional para os museus brasileiros. O documento desse Encontro ficou conhecido como a Carta de Petrópolis, redigida a partir das propostas encaminhadas pelos educadores e diretores de instituições museais participantes, levando em conta o Estatuto de Museus, a Lei 11.904 de 14 de Janeiro de 2009. O artigo $1^{\circ}$ desse Estatuto define Museu como instituição sem fins lucrativos que conserva, investiga, comunica, interpreta e expõe, para fins de preservação, estudo, pesquisa, educação, contemplação e turismo, conjuntos e coleções de valor histórico, artístico, científico, técnico ou de qualquer outra natureza cultural, aberta ao público, a serviço da sociedade e de seu desenvolvimento.

O Estatuto de Museus destaca que essas instituições deverão promover ações educativas, fundamentadas no respeito à diversidade cultural e na participação comunitária, contribuindo "[...] para ampliar o acesso da sociedade às manifestações culturais e ao patrimônio material e 
imaterial da Nação" (BRASIL, 2009). As ações educativas deverão estar explicitadas no Plano Museológico, no item referente ao Programa Educativo e Cultural, que abrange os projetos e atividades educativo-culturais desenvolvidos pelo museu, destinados a públicos diversos e articulados com diferentes instituições. Em seus princípios, a PNEM define Educação Museal como "um processo de múltiplas dimensões de ordem teórica, prática e de planejamento, em permanente diálogo com o museu e a sociedade" (IBRAM, 2017 , p. 4). e visa garantir que cada instituição possua setor de educação museal, composto por uma equipe multidisciplinar com a mesma equivalência no organograma para os demais setores técnicos do museu, "prevendo dotação orçamentária e participação nas esferas decisórias do museu" (IBRAM, 2017, p. 4). Enfatiza, no seu quarto princípio, que cada museu deverá construir e atualizar sistematicamente o Programa Educativo e Cultural, entendido como uma política educacional, em consonância ao Plano Museológico, levando em consideração as características institucionais e dos seus diferentes públicos, explicitando os conceitos e referenciais teóricos e metodológicos que embasam o desenvolvimento das ações educativas.

É a partir do quarto princípio da PNEM, expresso na necessidade dos Planos Museológicos explicitarem conceitos, referênciais teóricos e metodológicos, que se justifica a produção deste artigo, fruto de uma pesquisa bibliográfica, com o objetivo de apresentar os referênciais que tem orientado as ações educativas das instituições museológicas de Artes Visuais ao longo do século XX. Para tanto, inicia apresentando algumas ideias, representações de museus, seguidas das principais teorias e metodologias que tem norteado as ações dos serviços educativos de museus, os posicionamentos contemporâneos do século XXI e, por fim, as considerações alcançadas até o momento com este estudo. 


\section{Ideias de Museus}

A etimologia da palavra museu, origina-se no grego Mouseîn, que significa, templo das Musas. O museu é, para Eco (2005), por definição, voraz, pois nasce da rapinagem, de um suposto direito de conquista travestido de coleção privada que quer ser, ao mesmo tempo tesouro e teatro do mundo. O gosto pela acumulação também se encontra nas primeiras Galerías de pintura e escultura, como na Galeria Uffizi (1561), Itália, a princípio destinada à administração pública da região da Toscana, que recebeu, em 1581, a coleção de Francesco I, ampliada graças ao mesmo hábito colecionista acumulador das suas gerações subsequentes. Esse gosto pelo amontoado de pinturas e esculturas está representado nos quadros de Giovanni Paolo Pannini (1691-1765), especialmente na tela "Galeria de Vistas da Roma Antiga", de 1758, atualmente pertencente ao acervo do Museu do Louvre, França.

Contrário às acumulações dos e nos museus de arte, em geral com demasiadas obras fora de contexto que fatigam olhos e mentes, Eco (2005) esboça seu ideal de museu de uma única obra. Exemplifica esse museu tomando por exemplo a pintura de Sandro Boticcelli (1445-1510), A Primavera (c. 1482), hoje pertencente ao acervo da Galeria Uffizi, Itália. Para Eco (2005) todos os espaços estariam destinados a compreender essa obra, introduzindo o visitante na Florença da época de Boticcelli, a cultura humanística, o fermento místico daquele momento histórico no qual também pintavam outros artistas e as relações entre a pintura de Boticcelli e de outros pintores, tanto daqueles que o precederam como aqueles que nele se inspiraram. Também estariam expostos livros e gravuras da época, pinturas que informassem como a mulher era vista naquele momento histórico, e se poderia ouvir a música que, provavelmente, Boticcelli ouvira na época, bem como textos de filósofos e poetas, documentos sobre a flora e fauna da época, a fim de entender como o pintor, a partir delas, criou suas flores e árvores. Esse museu ideal de uma única obra permitiria ver a pintura de 
Boticcelli como um florentino educado do Quattrocento, tornando a visita uma experiência memorável.

A Revolução Francesa (1789 - 1799) é um marco na história e representação dos museus, pois com a tomada do poder pela burguesia foi necessário consolidar seu papel de classe dirigente, em substituição à aristocracia. O Museu do Louvre, na França, foi considerado o primeiro "Museu do Povo", no qual, durante o período inicial da mudança de regime político, qualquer cidadão podia entrar sem pagar. Como instituição social, os museus nasceram no final do século XVIII, mas seu desenvolvimento só se deu no século XIX.

A ideia de tudo acumular, a ideia de constituir uma espécie de arquivo geral, a vontade de encerrar em um lugar todos os tempos, todas as épocas, todos os gostos, a ideia de constituir um lugar de todos os tempos que esteja ele próprio fora do tempo, e inacessível à sua agressão, o projeto de organizar assim uma espécie de acumulação perpétua e indefinida do tempo num lugar que não mudaria, pois bem, tudo isso pertence à nossa modernidade. O museu e a biblioteca são heterotopias próprias à cultura ocidental do século XIX. (FOUCAULT, 2009, p. 419).

Michel Foucault (1926-1984) compreende o museu como uma heterotopia do tempo que se acumula infinitamente, como representação de qualquer lugar ou situação ideais em que vigorem normas e ou instituições políticas, supostamente aperfeiçoadas, um desses lugares reais, efetivos, que são delineados na própria instituição da sociedade, e que são:

[...] espécies de utopias efetivamente realizadas nas quais todos os posicionamentos que se podem encontrar no interior da cultura estão ao mesmo tempo representados, contestados e invertidos, espécies de lugares que estão fora de todos os lugares, embora eles sejam efetivamente localizáveis. (FOUCAULT, 2009, p. 415).

A partir da ideia de museu como uma heterotopia (FOUCAULT, 2009), como um lugar no qual todos os posicionamentos que se podem encontrar no interior da cultura estão, ao mesmo tempo, representados, contestados e 
invertidos, podemos nos perguntar como os museus brasileiros posicionam a produção cultural dos trabalhadores, das mulheres, das crianças, dos povos indígenas ou dos afrodescendentes no Brasil? Em que medida é possivel olhar para essa produção cultural nas instituições museais e, também, de que modo essas instituições olham para essa produção cultural?

Lara Filho (2012) destaca que ao longo do século XX a instituição museal tem privilegiado isoladamente um dos seus polos: ora o acervo, a coleção ora o público, o visitante. O autor destaca que o museu do século XXI, seja criado agora ou não, é uma instituição que se produz a partir das demandas da contemporaneidade, aquela que não focaliza um de seus polos isoladamente, mas se entende como um espaço de experiência ou um espaço relacional entre os mesmos. Para essa noção de museu como espaço relacional Lara Filho (2012) se apropria das ideias dos biólogos Humberto Maturana (1928) e Francisco Varela (1946-2001), para os quais a autoconsciência não está no cérebro, mas sim no espaço relacional que se constitui na linguagem. Lara Filho (2012) destaca que o curador Moacir dos Anjos também utiliza a expressão espaço relacional ao compreender que, na contemporaneidade, o museu é um espaço de construção de uma ideia de estar no mundo, um espaço relacional entre pessoas e coisas. Um museu como espaço relacional conta com uma curadoria que Lara Filho (2012) denomina de procedimental, aquela que busca abrir um leque de opções a partir de princípios organizadores de forma a possibilitar que os visitantes recombinem os dados, as informações, os objetos que lhe são expostos. Dessa forma a curadoria não teria por objetivo inculcar verdades nem fabricar leituras, mas criar diferentes patamares de leitura.

\section{Ações Educativas em Museus no Século XX}

Fróis (2008) informa que o serviço educativo de um museu foi teorizado, pela primeira vez, a finais do século XIX, na Alemanha, por Alfred 
Lichtwark (1852-1914). Entre os anos de 1886 e 1914 Alfred Lichtwark foi diretor do Museu de Arte de Hamburgo e protagonista do movimento de educação estética na Europa. Compreendia o museu como um território para a educação cultural e artística dos indivíduos e a estratégia proposta para a ação educativa foi a da percepção analítica das obras de arte a ser conduzida pela indagação socrática, a fim de que o visitante centrasse sua atenção nos detalhes visuais das obras. Alfred Lichtwark contou com a colabração de George Kerschensteiner (1854-1932), impulsionador do movimento "Escola Nova", também conhecido como "Escola Ativa" ou "Escola Progressista", e juntos defenderam a ideia da abertura dos museus de arte a públicos mais jovens.

Assim como na Alemanha, nos Estados Unidos as primeiras noções de serviço educativo estão vinculadas às teorizações da "Escola Nova". As pioneiras ideias para educação museal dos estadunidenses Albert Barnes (1872-1951) e Thomas Munro (1901-1973) dialogovam com a filososfia de John Dewey (1859-1952), expressa no livro A Arte como Experiencia (FRÓIS, 2008). Nessa obra, publicada na década de 1930 nos Estados Unidos, Dewey (2010) apresenta a arte inegrando os propósitos e valores da vida, pois a arte emerge nos processos de interação entre o organismo e o meio, que denomina de experiência. Quando os objetos artísticos são separados das condições de origem e funcionamento na experiência, se opacifica sua significação. Os museus e galerias, que recolhem e armazenam obras de arte segregam a arte em vez de considerá-la um fator concomitante da vida associativa. Dewey (2010) alertava para um tipo de museu que funcionava como "memoriais da ascensão do nacionalismo e do imperialismo" dedicados a exibir "a pilhagem recolhida por seus monarcas na conquista de outras nações" os quais atestariam "[...] a ligação entre a moderna segregação da arte e o nacionalismo e o militarismo". (DEWEY, 2010, p. 67).

As ideias escolanovistas no desenvolvimento do serviço educativo dos museus no Brasil também estão indicadas por Cabral; Rangel (2008), pois a criação do Ministério da Educação e Saúde, em 1930, e a atuação de 
educadores como Edgar Roquette- Pinto (1884 - 1954) e Anísio Teixeira (1900 - 1971), para o qual os museus e bibliotecas as instituições básicas da educação e "Não seria absurdo dizer que, em verdade, antecedem à escola. Pois esta só pode realmente educar, se tiver a nação um sistema de bibliotecas e museus". (TEIXEIRA, 1956).

Desde seus inícios a educação em museus, segundo Frois (2008), foi pensada como um auxílio à pedagogia da exposição, configurada no contexto de uma ideologia da falta que apela à lógica do suplemento. Para esse autor, a ideologia da falta provocou, em muitas situações, como recurso estável, o surgimento da escolarização das práticas dos museus e o domínio da palavra. Essa falta nunca foi preenchida e resolvida, por isso o discurso da eudcação nos museus tem acompanhado a tradição escolar dominante que privilegia o verbal como forma purificada da comunicação do significado. Fróis (2008) ratifica que mesmo nos museus de arte a palavra continua a ser o símbolo da experiência mental e do pensamento que tornou-se, em parte, na sua estrutura operativa, extensão do discurso escolar e, juntos, colonizaram o espaço da interpretação. Esse discurso escolar costuma infantilizar os públicos ou retirar das expressões artísticas seu inerente poder interpretativo. Esse modelo pedagógico dos museus tem sido contestado porém, em geral, essa contestação constituiu-se na substituição por outros esquemas que a própria instituição escolar também utilizou, ao longo do século XX, para contrapor-se ao modelo behaviorista, oscilando entre dois grandes posicionamentos pedagógicos: um derivado da metáfora do "construtivismo" e outro do modelo hermenêutico ou da compreensibilidade.

Padró, López e Kivatinetz (2014) identificam cinco tendências na educação museal. As autoras observam que a classificação dessas tendências, compreendidas como uma orientação comum entre os profissionais da educação museal, têm um fim didático, porém elas não são homogêneas e consideram possivel que coexistam, em uma mesma instituição, diferentes perspectivas podendo conviver pacificamente ou 
enfrentar-se na disputa pela hegemonia. As autoras denominam essas cinco tendências em: canônica, instrutora, por descoberta, constrututivista e reconstrutora. A tendência canônica parte da apreciação artística e da concepção de que os objetos expostos perdem sua função original para ganharem a imortalidade. A exposição é sinônimo de experiência estética como contemplação e, portanto, são os curadores os responsáveis pela tarefa educativa pelo mero feito de organizar a exposição das peças. Essa tendência compreende o museu como um cenário de ritual com a intencionalidade de purificar a identidade e restaurar a pessoa, por isso enfatiza narrativas fundacionais da instituição artística, destacando o relevante papel do colecionador, do artista, do curador. Pressupõe que todos os visitantes chegam ao museu com a mesma bagagem cultural, expectativas, motivações, desejos e formas de aprender. Espera que o público adote um papel passivo, silencioso que favorece a reprodução de uma narrativa baseada no prestígio da cultura dominante que hierarquiza as relações entre produtores e receptores. Em geral, organiza percursos a partir de uma estrutura linear e cronológica; guias didáticas com muita informação descritiva, acumulando fatos, conceitos, estimulando atitudes de admiração para o exposto. Dispensa a figura do educador, pois além da seleção de obras, cabe a curadoria definir o percurso, a ordem da exposição, elaborar textos de apresentação, geralmente breves e complexos, nos quais se descrevem as obras com uma linguagem compreensivel somente para os visitantes familiarizados com a tradição da história da arte. Para a tendência canônica a experiência da visita ao museu se justifica pelo conhecimento sofisticado que esta proporciona.

A tendência instrutora considera o museu como o lugar em que o conhecimento se transmite de forma unidirecional, no qual o visitante passivo tem que aprender aquilo que o curador selecionou para a exposição. O museu prima pela sua função didática e oferece ao público a atividade denominada de visitas guiadas. Essa tendência consolidou-se no período de formação dos Estados-Nação, na Europa do século XIX, quando escola e 
museu eram lugares de e para a educação cívica. De um modo geral, as exposições instrutoras se ordenam de forma sequencial com um princípio e um final chave, com uma ordem cronológica e com a apresentação da informação a partir da estratégia de pequenos passos, organizados do mais simples ao mais complexo. Nessa perspectiva o museu é um instrumento para a educação moral, verdades e valores universais. O educador é compreendido como um guia, ou monitor, que dirige a visita guiada pelo percurso fixo da exposição. Parte-se do pressuposto que todos os visitantes aprendem da mesma forma e o papel do museu é divulgar os mesmos conceitos adaptados para as diferentes faixas etárias. Em geral se organizam atividades dirigidas a dois segmentos de visitantes: comunidades escolares e famílias, às quais se costuma oferecer visitas com uma oficina. Padró, López e Kivatinetz (2014) destacam que para a tendência instrutora, as exposições e recursos educativos possuem uma estrutura fixa, linear e univoca, que privilegia a voz do curador em torno de um discurso, supostamente, objetivo, neutro e universal. Geralmente o percurso se inicia com um texto que costuma ser anônimo e de difícil compreensão. O educador tem a missão de reproduzir o discurso unívoco, elitista e autoritário do especialista da curadoria que não demanda a participação do visitante considerado como uma massa uniforme que deve ser controlada e ensinada a partir dessa organização didática.

A tendência por descoberta se consolida durante as décadas de 1960 e 1970 predominante no período da renovação da museologia tradicional. Padró, López e Kivatinetz (2014) observam que essa tendência recupera as ideias de John Dewey somadas à teoria do desenvolvimento psicossocial de Erik Erikson (1902 - 1994), enfatizando a aprendizagem ao longo da vida. Para essa tendência os museus são lugares de descobrimento, diversão, pontos de encontro da comunidade, centros culturais vivos. Se organizam exposições "hands on", nas quais o visitante pode manipular artefatos, falar, escutar e ler para aprender a partir da sua própria experiência sensorial. Essas exposições procuram combinar três formas de interatividade nas 
quais se enfatizam os aspectos sensoriais, a interatividade manual, com as mãos em ação, os aspectos mentais, com ideias em ação e emocionais, com o coração em ação. Se concebe a aprendizagem como uma atividade indutiva na qual o sujeito parte de suas experiências imediatas e busca por si mesmo as respostas. A educação é entendida como um processo de participação ativa do visitante e o espaço museal como um lugar de ócio e entretenimento. O foco de interesse está no aprendiz que tem seus cinco sentidos ativados por meio de estratégias como jogos de caça ao tesouro, que solicitam ao visitante buscar a partir de pistas. Apesar da diversidade das estratégias, os jogos propostos levam a uma única solução. As exposições expandem a noção de coleção oferecendo reproduções de obras, demonstrações de processos de criação, entre outros. O serviço educativo tem uma posição central no museu, pois se encarrega de fomentar todas as experiências interativas para a formação do público. Compreende-se o educador como um facilitador que estimula a participação ativa do público, cuja função primordial é a de aproximar o museu do público por meio de perguntas que buscam elucidar uma mensagem predeterminada que deve ser aprendida. As exposições priorizam a experiência do visitante, entendido como um educando dinâmico, capaz de pensar a partir daquilo que vê, que gera perguntas e busca respostas por meio de suas observações. Apesar da participação que se admite aos visitantes, é sempre o educador quem oferece a única verdade da exposição ao público, produzindo um conhecimento que se gera de cima para baixo.

A tendência construtivista baseia-se na metáfora do construtivismo. Essa tendência considera que aprender no museu é diferente da aprendizagem escolar, pois os museus são considerados lugares de educação não formal. Também são considerados como lugares capazes de combater a exclusão social, promover a cidadania ativa, o desenvolvimento pessoal e a inovação. Por isso oferecem diferentes atividades dirigidas a todas as idades individual e coletivamente. Aposta por uma diversidade de perspectivas, pois entende que os diversos públicos trazem diferentes bagagens e experiências 
culturais. A finalidade do serviço educativo é a de promover outras "visões", além das versões oficiais. Desse modo, a investigação sobre as percepções, atitudes, valores e maneiras de compreender do público são cruciais para desfazer as suposições que o público têm sobre o museu. Padró, López e Kivatinetz (2014) observam que para a tendência construtivista é papel do museu desenvolver uma política educativa que facilite a inclusão da cultura do visitante. Para isso se criam redes de colaboração com coletivos de artistas e profissionais de outros setores para gerar oportunidades para os diversos estilos de aprendizagem e níveis de compreensão dos visitantes. Essa tendência fomenta políticas de pesquisa e avaliação, pois o serviço educativo, integrado em uma estrutura museal mais flexivel, necessita conhecer o público visitante. Se enfatiza que o público visitante também tem um conhecimento, bem como seus preconceitos, ideias, formas de pensar sobre os saberes e significados que o museu produz. A tendência construtivista busca que o visitante, a partir de sua própria bagagem e da experiência mediada com os elementos presentes no museu, construa seu conhecimento. Pretende integrar o conhecimento que o visitante traz com o que se forja na instituição, organizando exposições, atividades e recursos que focalizam o aprendiz mais que o conteúdo a ser aprendido. O educador é considerado como um regente de orquestra que harmoniza diversas perspectivas ajudando o visitante a conectar seu mundo com os objetos e ideias da exposição por meio do diálogo, pois aprender é uma atividade social, baseada na motivação que acontece na interação, na experiência e no contexto. Os profissionais do museu são compreendidos como uma comunidade de aprendizes e cabe ao serviço educativo implementar programas com a finalidade de facilitar o acesso do público às coleções, estimulando o diálogo para que cada visitante construa sua própria interpretação dos objetos e possa compreendê-los de forma aberta. Os educadores são conscientes de que nem todos os visitantes poderão construir o mesmo conhecimento a partir das mesmas perguntas, pois as conexões que cada visitante será capaz de fazer dependem de suas 
experiências ou saberes prévios. A tendência construtivista foca sua atenção no público, dado que o conhecimento não é independente do aprendiz e sua aprendizagem parte de uma estrutura de conhecimento prévio que alavanca os novos conceitos. Isso quer dizer que o visitante não inclui novos fatos ao que já conhece, mas reorganiza constantemente seus sistemas de informação, chegando à compreensão enquanto interage com o seu meio. Para a tendência construtivista o educador e o visitante participam ativamente na construção de uma identidade compatível com o desejo de ser educado.

A tendência reconstrutora compreende a ação educativa do museu como um ato de conferir poder aos visitantes e os departamentos da instituição como zonas de contestação das politicas oficiais que ajudam a reinventar a interpretação conferida em programas expositivos. Essa tendência pretende enfatizar a interação entre diferentes culturas e a autoridade compartilhada entre grupos que podem organizar exposições ou mediar ações, questionando a legitimidade dos museus como produtores de significados. Inspira-se na chamada pedagogia crítica que questiona os processos de genealogia cultural, de memória social e de contexto. Considera que os museus devem reinventar-se e repensar-se como instituição legitimadora de significados hierárquicos. Por isso indaga sobre quem fala, em quais circunstâncias o faz, como o faz e em nome de quem o faz, para a tomada de consciência das vozes que o museu produz, bem como daquelas que omite. Para a tendência reconstrutora é importante saber como se constrói a diferença e questioná-la tanto nas exposições temporais como nas releituras das coleções permanentes. Essa tendência não compreende a cultura como monolítica e imutável, mas um espaço mutante de linguagens, experiências e vozes em meio de diversas relações de poder e privilégio. Consequentemente, se considera o museu como uma esfera pública na qual os profissionais devem ser conscientes de sua influência para tornar mais democrática a realidade. Compreende a educação museal como uma teoria e uma prática, sem a tradicional dicotomia entre 
ação/pensamento. Esse trabalho se fundamenta no referencial teórico do reconstrucionismo social, que parte de quatro pressupostos básicos: aquilo que se considera conhecimento do mundo não é um produto da indução ou da construção de hipóteses gerais, mas sim fruto da mediação cultural, a história e o contexto social; a forma pela qual entendemos o mundo é o resultado da mediação entre sujeitos que estão historicamente situados e que se relacionam com os artefatos sociais, logo o processo de compreensão não está determinado pela natureza mas se negocia entre as pessoas por meio de suas relações, como, por exemplo as noções de infância, mulher entre outros; a compreensão do mundo se relaciona com os processos sociais de comunicação, negociação, conflito; conectamos e negociamos formas de compreender com o pensamento dicotômico. As ações educativas que se fundamentam nessa teoria procura oferecer dilemas ao visitante e tornar visiveis as relações de saber e poder, se posicionando em questões de gênero, raça, classe, religião. Reconhece o museu como uma instituição política e procurará oferecer informação polivocal, de diferentes vozes que se conectem, integrando as vozes dos educadores e visitantes no discurso expositivo. Padró, López e Kivatinetz (2014) afirmam que a compreensão da educação museal a partir de um sentido crítico, polifônico e revisionista também conta com as contribuições teóricas dos Estudos Culturais, que enfatizam a reconstrução dos museus desmascarando as estruturas de poder e mediação vinculadas a uma narrativa hegemônica, patriarcal e colonial. Para os pressupostos dos Estudos Culturais, as identidades se constroem por meio de narrativas que são produto das trocas culturais, sendo fundamental apontar quais mitos, categorias, estereótipos e suposições têm sido sustentados pelas instituições museológicas. Portanto, a educação museal também produz posicionamentos e diferenças de gênero, classe, raça, sexualidade, logo o educador do museu não pode ser um mero receptor ou reprodutor das narrativas institucionais, mas um intelectual que contribui para rediscutir questões de supremacia e autoridade. Os programas educativos vinculados à tendência reconstrutora defendem a 
ideia de museus como geradores de conhecimento e não receptores para deslocalizar o conhecimento, para apresentar a verdade, um conhecimento dirigido à interpretação e a representação. Isso quer dizer que reconhecem que as exposições interpretam e representam aos que a expõem, ou seja, a instituição, os organizadores, os curadores. Dependendo do que se exponha, como se exponha, como se posicione, se organize e se fale sobre essa exposição, esta poderá promover uma ou outra visão. A tendência reconstrutora concebe a educação museal como um ato de reflexão e criação de novas narrativas, igualmente válidas e tão significativas como a proposta pela instituição. Consequentemente, entende o visitante como uma pessoa reflexiva que, motivada pelo educador, constrói suas próprias histórias tendo em conta seu conhecimento prévio e a experiência da visita.

Dando preferência à noção de paradigma, como modelo e padrão, em vez de tendência, como orientação comum, Vianna (2017) identifica três grandes paradigmas para as atividades de artes visuais, tanto nos espaços expositivos como na sala de aula, nomeando-os de: tradicional, dialético e emergente. A autora destaca que para cada um desses paradigmas correspondem concepções específicas de patrimônio, educação e discurso. $\mathrm{O}$ paradigma tradicional procura explicar ao público o valor representado pelo acervo do museu que tem a função básica de conservar determinado patrimônio material. As exposições organizadas, em geral, por ordem cronológica, traduzem a intenção de legitimar e estender o alcance desse determinado patrimônio por meio de uma visita de caráter ritual, centrada na visão e no pensamento conceitual. Elas oferecem uma representação clara e convincente, que usa a autoridade dos especialistas para guiar o visitante, com um discurso informativo, diretivo e reprodutor. O educador tem a função de validar a fala do curador fornecendo informações que permitam ao visitante aproximar-se do código de linguagem utilizado no texto curatorial e situar o objeto em seu contexto de origem. A noção de patrimônio cultural nesse paradigma é a do bem comum a ser repartido com uma concepção hierárquica de ascensão cultural. 
O paradigma dialético procura equilibrar o conhecimento do aprendiz iniciante e o do especialista. Considera que um aprendiz iniciante é capaz de ver e entender muita coisa com base em sua experiência de vida, porém determinados modos de compreensão das artes visuais permanecerão fora do seu alcance, a menos que ele adquira certos tipos de conhecimento e habilidades por meio de uma mediação generosa e articulada. A visita integra elementos rituais e lúdicos, incluindo os objetos da exposição e a bagagem cultural do visitante, suas expectativas e competências de leitura. Vianna (2017) observa que as ações educativas fundamentadas no paradigma dialético encorajam a intuição do visitante ao mesmo tempo que oferece informação apropriada, problematizando visões ingênuas ou preconceituosas, com a intenção de provocar situações capazes de ampliar a experiência em arte. Consequentemente, o discurso do educador precisa conciliar o espírito de partilha de valores e tradições, a manutenção dos valores hegemônicos do sistema artístico com a proposta de socialização da experiência estética, de aprender experimentando com prazer. Portanto, o serviço educativo explora a tensão provocada pelo deslocamento entre os valores hegemônicos e a bagagem cultural do visitante.

O paradigma emergente enfatiza duas questões: a do papel ativo do leitor na construção do significado e a possibilidade de múltiplas interpretações de um texto. Nesse paradigma o educador privilegia a construção de significados com base nos conhecimentos e experiências do visitante. Sustenta que uma exposição deve mostrar o contexto social que produz o significado. O conteúdo e o valor estético do que é exposto não é tão importante quanto o diálogo que se produz entre o visitante e os objetos e conceitos que constituem o discurso expográfico. A visita se caracteriza pelo caráter lúdico e pela participação ativa do visitante, permitindo a entrada da subjetividade, das emoções e das sensações corporais. Vianna (2017) identifica uma série de metodologias no paradigma emergente, como as Estratégias do Pensamento Visual (Visual Thinking Strategies, VTS) criada pelos estadunidenses Abgail Houssen e Philip Yenawine, bem como o roteiro 


\section{8}

de análise formal de Rod Taylor (conteúdo, forma, processo, expressão) e os critérios de julgamento (arbitrário, habilidade/técnica, materiais, expressivo, linguagem visual e contextual), do britânico John Bowden. O fundamento do paradigma emergente é o reconhecimento do direito de cada pessoa a uma interpretação que se traduz em uma prática interativa e dialógica.

\section{Posicionamentos Contemporâneos}

Como apresentado no tópico inicial, Foucault (2009) desenvolve a ideia de museu como uma heterotopia do tempo, própria das culturas ocidentais do século XIX. O desafio posto à instituição museal do século XXI é o fato de já não estarmos na época do tempo, mas sim do espaço, da justaposição do próximo e do longínquo, do lado a lado, do disperso. Estamos em um momento em que o mundo se experimenta:

[... como uma rede que religa pontos e que entrecruza sua trama. Talvez se pudesse dizer que certos conflitos ideológicos que animam as polêmicas de hoje em dia se desencadeiam entre os piedosos descendentes do tempo e os habitantes encarniçados do espaço. (FOUCAULT, 2009, p. 411).

Nessa polêmica entre devotados descendentes do tempo e obstinados habitantes do espaço, Serdio (2011) observa que não faltam receituários baseados em premissas conceituais com as quais é dificil estar em desacordo, posto que estas dão asas a um certo afã de transformação radical. Situando-se no contexto concreto da educação em museus, a autora observa que um dos modelos teóricos que tem tido relevância nos últimos anos é o das pedagogias críticas, que animam a tendência reconstrutora (PADRÓ; LÓPEZ; KIVATINETZ, 2014), explicitada no tópico anterior. No rastro dos mitos repressivos, subjacentes às premissas emancipadoras das pedagogias criticas, levantados por Elizabeth Ellsworth em seus escritos sobre "modos de endereçamento", Serdio (2011) aponta para os pressupostos racionalistas, a partir dos quais, as pedagogias críticas consideram que é 
possivel o sujeito reconhecer de maneira plena e consciente a opressão. Também o pressuposto da autoridade docente, como sendo a orquestradora do processo emancipador e sua implicação inquestionável em redes de subalternidade, bem como seu poder para dotar de voz ao outro silencioso, silenciado e oprimido. Serdio (2011) afirma que questionar esses pressupostos não implica descartar as pedagogias críticas como referência para imaginar possíveis transformações nas práticas educativas, porém o modo de nos relacionarmos com essas perspectivas necessita mudar se mantém-se o desejo de serem verdadeiramente críticas e não um dogma de fé pedagógica. A autora sinaliza que em vez de aplicar princípios previamente definidos, se trataria de questionar seus pressupostos desde nosso lugar e circunstância. Isso quer dizer que as pedagogias críticas nos convidam a refletir sobre nosso próprio posicionamento e crenças, o que inclui explorar nossos limites e preconceitos, nossos condicionamentos pessoais e estruturais. Também há de se ter em conta a dimensão institucional, de maneira que não podemos falar de conteúdos críticos se estes não são discutidos pela e na própria organização e articulação relacional do projeto. Consequentemente, as pedagogias criticas não consistem em uns conhecimentos que se adquirem, mas implicam em uma transformação das formas de relacionar-nos e de atuarmos nos contextos educativos em suas dimensões pessoais e institucionais. Significa utilizar as perspectivas criticas como referentes de análise do que realmente acontece e que, com toda a probabilidade, será muito diferente do que o modelo teórico induz a pensar que deveria suceder. Pode acontecer de que visitantes e estudantes não estejam propensos a opor-se à ideologia opressora daquilo que lhes parece prazeroso, ou que sejam perfeitamente capazes de criticá-la sem por isso pensar de deixar de desfrutá-la. A autora questiona se seria possivel forçar uma atitude crítica e responde que trata-se de uma solução contraditória para um enfoque supostamente crítico. São essas contradições as que oferecem uma aproximação a outras perspectivas problematizadoras, pois em vez de sucumbir à tentação da retórica transformadora radical seria 
fundamental focar nas negociações e resistências que emergem em projetos que atendam aos desejos e limitações dos participantes reais, sem transformá-los em atores de alguma representação emancipadora prescrita, mas em experiências que, mesmo pequenas de início, são deliberadas transformações nas estruturas institucionais, sempre precárias, mas não menos importantes.

Os "modos de endereçamento" (ELLSWORTH, 2001) são uma das pistas contemporâneas apontadas por educadoras de museus, como Serdio (2011), Padró (2011) e Acaso (2011), para os desafios do século XXI. Trata-se de um conceito que tem sua origem nos estudos de cinema para se pensar a relação dos artefatos culturais e a experiência do espectador. O modo de endereçamento não é algo que faça parte do artefato cultural em si mesmo, mas um evento, uma interação entre o individual e o social, um espaço relacional entre o artefato cultual e as apropriações que o espectador realiza a partir dele. O entendimento do modo de endereçamento como um evento, um acontecimento levou o conceito para os Estudos Culturais, para a Educação e Psicanálise. No campo educativo pode-se pensar na interação entre os posicionamentos que educadores oferecem ao participante, quem o educador pensa que seja o participante, incluindo como o participante se posiciona em função desse contexto criado. "O modo de endereçamento não é um momento visual ou falado, mas uma estruturação, que se desenvolve ao longo do tempo, das relações entre o filme e seus espectadores" (ELLSWORTH, 2001, p. 17). Desse modo, não há nenhuma garantia de resposta a um determinado modo de endereçamento, pois este não é um meio para se conseguir as respostas previstas e desejadas pelos educadores. Nesse caso a atenção está nos espaços das diferenças entre como educadores endereçam o participante e em como os participantes respondem. São esses espaços das diferenças que podem oferecem subsídios aos educadores para que conheçam as diversidades sociais, culturais e individuais dos participantes. 
Ellsworth (2005) também discute a noção do diálogo comunicativo das pedagogias críticas ao questionar a pretensa neutralidade e transparência sob a qual esse diálogo operaria, dado que este também situa os participantes em uma relação de poder na qual há uma clara divisão entre quem destina e quem consente. Padró (2011) parte das ideias de Ellsworth (2005) como referência ao afirmar que as ações de muitos serviços educativos ainda compreendem a aprendizagem como uma via de mão única, no sentido do museu para o visitante, porém se passarmos a ver de outra forma, se modificarmos o lugar da enunciação para os espaços das diferenças entre como educadores endereçam o participante e em como participantes respondem, a mediação no museu também poderá ser uma prática que nunca se completa nem se acaba, que não se resolve, mas, talvez, altere a realidade de alguma maneira e possibilite outras leituras.

Além do referencial teórico de Ellsworth (2001, 2005), Padró (2011) também apropria-se da teoria da performatividade, de Judith Butler, para compreender a educação museal. A autora indica que a performatividade (BUTLER, 2003) acontece naquelas ações sempre repetidas para representar algo mediante a estilização do corpo e que quando se altera nos damos conta de como aprendemos na repetição dos mesmos rituais, gestos, palavras que buscam um efeito de continuidade, que nos tranquilizam pela sua densidade e, por isso mesmo nunca colocamos em dúvida. Trata-se de ações reiteradas e obrigatórias em função de umas normas sociais que nos sobrepõem. Essas ações não são um fato isolado de seu contexto, mas sim uma prática social, uma reiteração continuada e constante na qual as normas se negociam. Desse modo atua-se como educadora de museu em função de determinadas normas que essa mesma atuação promove, legitima, sanciona e exclui.

Pedagogias regenerativas é a expressão escolhida por Acaso (2011) para pensar os desafios da educação museal a partir dos modos de endereçamento (ELLSWORTH, 2001, 2005) e da teoria da performatividade (BUTLER, 2003). A autora questiona o fato de muitos serviços educativos ainda desenvolverem práticas em uma única direção, baseadas no oral ou 
textual, com representantes institucionais adotando um papel colonial, patriarcal e autoritário, em salas fechadas nas quais não se pode falar em voz alta, nem tocar os objetos levando os corpos dos visitantes a adotarem uma posição de subordinação estática. Acaso (2011) sinaliza que é possivel subverter essas práticas se começarmos a assumir o ato de ver como um evento criativo e que a linguagem visual não é uma estratégia de comunicação nem de representação, mas sim um sistema performativo da realidade, que opera de maneira invisível na agência do espectador e que se faz necessário visibilizar. Assumir o poder performativo da linguagem visual nos levaria a entendê-la como uma força de transformação. A autora considera que assim como a teoria da performatividade reconhece que as palavras transcendem o fenômeno comunicativo e alteram a realidade, o mesmo ocorre com as imagens, pois o visual é o sistema principal que está transformando a realidade, performando nossos corpos, nossas ideias, nossos hábitos e que nos obriga a operar-nos, a mutilar-nos a nos autoflagelar. Longe de ser um mero instrumento de comunicação, a linguagem visual é a ferramenta que performa a realidade e para poder refletir sobre seu poder, os museus de artes visuais, as escolas, as universidades ou qualquer outro lugar educativo terá que começar a assumir e incorporar o protagonismo visual do mundo contemporâneo. Portanto, a linguagem visual tem que ser reconhecida como o principal recurso para revelar o posicionamento invisivel que os museus, e outros espaços educativos, mantém por meio do seu endereçamento pedagógico. A partir desses pressupostos, Acaso (2011) vem trabalhando no Projeto Museu Visível, que tem por objetivo explicitar como os atos visuais no museu, por meio da arquitetura, dos uniformes, dos folhetos, das páginas web, das montagens das exposições, posicionam os visitantes de determinado modo.

Martins (2016) parte do conceito de intercessores, de Deleuze (2008), para pensar o trabalho de aproximação da arte com o público do museu, não mais a partir de um ponto de origem, mas como inserção numa onda preexistente, um entrar em órbita, um se fazer aceitar pelo movimento, de 
chegar entre, em vez de ser origem de um esforço. Martins (2016) compreende o trabalho de mediação cultural como estar entres, e utiliza a escrita da letra esse em maiúscula para dar visibilidade à condição plural dos intercessores que podem ser muitos, sejam pessoas, coisas, fictícias ou reais, animadas ou inanimadas em que "cada um compreende a sua maneira a noção proposta pelo outro" (DELEUZE, 2008, p. 157). A autora propõe uma ação educativa que “[...] esteja em meio a, com o olhar/corpo inteligente, sensível, aberto e em vigilia criativa; somando vozes para ver mais, ouvir mais, pensar mais". (MARTINS, 2016, p. 3).

Tal como a contemporaneidade permite o acesso a inúmeras obras de tempos e lugares diversos que, consequentemente, representam olhares e pensares específicos, hoje essas obras convivem entre si conosco cruzando diversas representações de arte -tais como o desejo da cópia da realidade, da espontaneidade da criação ou da provocação para a participação- Martins (2016) considera que no trabalho de aproximação da arte com o público encontramos esse mesmo cruzamento e justaposição de representações de ações educativas, pois encontramos aquelas que tudo pretendem explicar valorizando as informações, como também as que querem dar visibilidade aos processos criativos, ou as que valorizam as rupturas e também as que provocam o outro a pensar junto, a somar as suas vozes. A autora posicionase nessa última atitude, pois afirma que mediar é estar entre muitos. Indica que essa mediação implica um tecer sem início e sem fim, dado que os vários fios, das tramas e da urdidura, trazem inúmeras marcas da história e da cultura esgarçados pelos contextos de suas texturas, em fluxos sempre partilhados.

\section{Considerações Transitórias}

A Política Educacional de cada Museu está vinculada à representação que a instituição museal constrói para si e, consequentemente, os referenciais teóricos e metodológicos adotados estarão em consonância a 
essa representação. Desde as suas origens, está implícita no museu a ideia de templo, de oferenda para contemplação. Essa prazerosa dimensão visual é inerente a própria concepção de museu, porém ao longo do século $\mathrm{XX}$ as ações educativas dessa instituição tem corrido em paralelo com a tradição escolar dominante, privilegiando o verbal como forma primordial da comunicação do significado.

Os diversos autores consultados classificam as ações educativas em museus em torno de tendências, compreendidas como uma orientação comum entre os profissionais da área, ou como paradigmas, modelos que, por períodos mais ou menos longos, de modo mais ou menos explícito, orientam a busca de soluções para os problemas por eles suscitados. Independente dos modos de classificação dos referências teóricos e metodológicos que os autores consultados oferecem, encontramos uma característica comum nessas tendências e paradigmas do século XX. Estas constróem-se sobre um pensamento de oposição dual hierarquizada entre acervo/coleção e visitante que pretende conseguir as respostas previstas e desejadas por curadores e ou educadores. Esse pensamento dicotômico e hierarquizador origina propostas normativas, prescritivas, muitas vezes contraditórias, de um dever ser, que separa os que pensam, planejam as atividades dos museus daqueles que as realizam. Essas normas prescritivas se repetem em reiterados rituais de exibição, gestos de curadores, guias, monitores, vigilantes, educadores, facilitadores e visitantes que nos tranquilizam pela sua densididade e, dificilmente, os colocamos em duvida. Parece natural essa ação unidirecional, univocal da instituição museal para o público e atuamos em função dessas normas de modo que nossa atuação também promove, legitima e sanciona essas prescrições.

Pensar um museu do século XXI como um espaço relacional entre pessoas e coisas nos desafia a construir um outro modo de ver a própria linguagem visual e a prazerosa dimensão visual desses espaços. Ver como os atos visuais do e no museu, seja por meio da arquitetura, das salas, corredores, rampas, iluminações, uniformes, catálogos, disposição de 
objetos, das páginas web, do deslocamento de pessoas, endereçam as ações educativas. Compreender como a linguagem visual é um sistema performativo da realidade, que opera na agência dos profissionais da instituição museal e visitantes, performando nossos corpos, nossas ideias, nossos hábitos. Ver o espaço relacional sem um ponto de partida, de origem, mas inserindo-se no movimento vibratório e ondulatório dos muitos intercessores que transitam entre coisas e pessoas, implica aceitar o ambíguo poder de dissimular pela simulação da similitude, de mostrar mentiras que se assemelham a verdades e, também dar a ver as imagens que, sempre, a partir de um determinado ponto de vista, nos posicionam provocando associações que os interesses que as produziram não autorizaram e nem sequer imaginaram.

\section{Referências}

ACASO, Maria. Del paradigma modernista al posmuseo: seis retos a partir del giro educativo (¿Lo intentamos?) In: ACASO, Maria (Coord.) Perspectivas: Situación actual de la educación en los museos de artes visuales. Madrid: Editorial Ariel/Fundación Telefónica, 2011. p. 30-38.

BRASIL. Estatuto de Museus. Decreto-Lei n. ${ }^{\circ} 11.904$, de 14 de janeiro de 2009. Disponível em: <http://corem1r.com/pdf/lei_11904.pdf> Acesso em: $15 / 07 / 2017$.

- Ministério da Cultura. Bases para a Política Nacional de Museus: memória e cidadania. Brasília, Minc: 2003.

BUTLER, Judith. Problemas de gênero: feminismo e subversão de identidade. Rio de Janeiro, RJ: Civilização Brasileira, 2003.

CABRAL, Magaly; RANGEL, Aparecida. A curadoria de processos educativos de ações esparsas à curadoria. In: JULIÃO, Letícia; BITTENCOURT, José Neves (Org.) Cadernos de diretrizes museológicas 2: mediação em museus: curadorias, exposições, ação educativa. Belo Horizonte: Secretaria de Estado de Cultura de Minas Gerais, Superintendência de Museus, 2008. p. 168 178. 
DELEUZE, Gilles. Os Intercessores. In: Conversações, 1972-1990. Rio de Janeiro: Ed. 34, 2008. p. 151-168.

DEWEY, John. Arte como Experiência. São Paulo, SP: Martins Fontes, 2010.

ECO, Umberto. El museo en el tercer milenio. Revista de Ocidente, n. 290291, p. 33-53, 2005.

ELLSWORTH, Elizabeth. Modos de endereçamento: uma coisa de cinema; uma coisa de educação também. In: SILVA, Tomaz Tadeu. (Org.). Nunca fomos humanos: nos rastros do sujeito. Belo Horizonte, MG: Autêntica, 2001.

FOUCAULT, Michel. Ditos \& Escritos III: estética, literatura e pintura, música e cinema. 2. ed. Rio de Janeiro, RJ: Forense Universitária, 2009.

FRÓIS, João Pedro. Os Museus de Arte e a Educação: discursos e práticas contemporâneas. Revista Museologia.pt, n. 2, p. 62-75, 2008.

INSTITUTO BRASILEIRO DE MUSEUS, IBRAM. Política Nacional de Educação Museal. Brasília, DF: IBRAM, 2017.

LARA FILHO, Durval de. O museu no século XXI ou o museu do Século XXI? Periódico Permanente. v.1, n.1, 2012. Disponivel em: $<$ http://www.forumpermanente.org/revista/edicao-0/textos/o-museu-noseculo-xxi>. Acesso em: 15 jul. 2017.

MARTINS, Mirian Celeste. Mediação cultural: [entre] laçamentos de territórios da arte e cultura e curadorias educativas. Revista Matéria-Prima, v. 4, n. 1, p. 28-38, jan./abr. 2016.

PADRÓ, Carla. La culpa es del swing o ¿por qué no hablamos de relaciones pedagógicas también en los museos? In: ACASO, Maria (Coord.) Perspectivas: situación actual de la educación en los museos de artes visuales. Madrid: Editorial Ariel/Fundación Telefónica, 2011. p. 52-55.

PADRÓ, Carla; LÓPEZ, Eneritz, KIVATINETZ, Magalí. Estilos de aprendizaje y metodologias para trabajar en Museos. In: PADRÓ, Carla (Edit.) Mediación Museística. Barcelona: Mapa de las Ideas, 2014. p. 89-104.

SERDIO, Aida Sánchez de. Las paradojas de la pedagogía crítica o la resistencia de la realidad. In: ACASO, Maria (Coord.) Perspectivas: Situación actual de la educación en los museos de artes visuales. Madrid: Editorial Ariel/Fundación Telefónica, 2011. p. 55-58. 
TEIXEIRA, Anisio. Bibliotecas e museus: instituições básicas. Uma entrevista do professor Anísio Teixeira. IBBD/Boletim Informativo, Rio de Janeiro, v. 2, n. 06, nov./dez., 1956.

VIANNA, Rachel de Souza. O discurso na mediação em Artes Visuais. In: ARSLAN, Luciana Mourão; MELO, Roberta Maira de. Artes visuais $e$ educação: ensino e formação. Uberlândia, MG: EDUFU, 2017. p. 103-125.

Recebido: 09 de agosto de 2017

Aceito: 26 de agosto de 2017

Publicado: 19 de setembro de 2017 